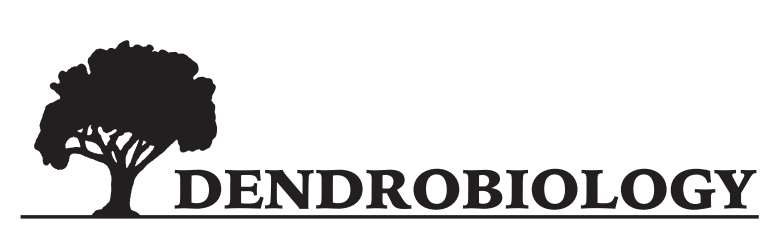

2020, vol. 83, 85-95

http://dx.doi.org/10.12657/denbio.083.009

\author{
Xiaoli Wang, Xiaona Kong, Yingwei Zhao, Yue Cao, Zilin Cao*
}

\title{
The endomycorrhizal fungal species and their effects on the growth and nutrient characteristics of Eucalyptus maidenii seedlings in China
}

Received: 27 November 2019; Accepted: 31 August 2020

\begin{abstract}
Eucalyptus maidenii plantations are typically fertilized to increase the yields of eucalyptus oil and timber. However, the application of chemical fertilizers is costly and can cause environmental pollution and soil erosion. Mycorrhiza fungi can facilitate the cultivation of optimal seedlings while promoting the growth of trees. To date, investigations into the inoculation of endomycorrhizal fungi to enhance the productivity of E. maidenii in Yunnan, China have not been undertaken.

The species/dominant species of endomycorrhizal fungi on E. maidenii in Yunnan were isolated and identified. The effect of endomycorrhizal fungi on E. maidenii was elucidated. The major species of endomycorrhizal fungi that affect $E$. maidenii were ascertained.

Bulk soil was collected from an E. maidenii plantation, and the species of endomycorrhizal fungi were investigated. The effect of the endomycorrhizal fungi on E. maidenii were analyzed via a single factor experimental design, where the number of spores of endomycorrhizal fungi in the seedling substrate were controlled. The major endomycorrhizal fungi species that affected E. maidenii were ascertained via stepwise regression analysis.

Five endomycorrhizal fungal species were isolated from the bulk soil, with the dominant being Glomus aggregatum and Glomus mosseae. With higher counts of endomycorrhizal fungal spores in the seedling substrate, the infection rate and intensity of seedlings were observed to increase, as well as the NPK concentrations of the bulk soil. With the increased nitrogen concentration in the bulk soil, the nitrogen concentration of the aerial components of the seedlings also increased. The NPK concentrations in the bulk soil and seedlings, the second order lateral roots, the root activity, and the seedling height were significantly promoted by the presence of endomycorrhizal fungi (the third experimental treatment).

The NPK concentrations of the bulk soil and seedlings, as well as the growth indices of seedlings increased through endomycorrhizal fungi inoculation. The major species of the endomycorrhizal fungi on E. maidenii were G. aggregatum, Glomus multicaule, and Claroideoglomus etunicatum.
\end{abstract}

Keywords: Eucalyptus maidenii, endomycorrhizal fungi, major species

Addresses: X. Wang, X. Kong, Y. Cao, Key Laboratory for Forest Resources Conservation and Utilization in the Southwest Mountains of China, Ministry of Education, Southwest Forestry University, Kunming, China

Y. Zhao, State-owned Dongmen Forest Farm in Guangxi, Fusui, China

Z. Cao, College of Ecology and Environment, Southwest Forestry University, Kunming, China, e-mail: fjcaozilin@sina.com

*Corresponding author 


\section{Introduction}

Eucalyptus maidenii has been extensively planted on a global scale due to its dual use for eucalyptus oil and timber. Owing to its broad ecological range, E. maidenii was initially introduced in Yunnan Province, China since 1951 (Wang, 2010; Zhou, 2011). At present, E. maidenii plantations are typically supplemented with chemical fertilizers to enhance the yields of eucalyptus oil and timber (Xiang et al., 2017; Omar et al., 2018). However, the application of chemical fertilizer is costly and can cause environmental contamination and soil erosion, which is not conducive to the sustainable management of $E$. maidenii (Ren et al., 2013). It was found that the mycorrhiza could facilitate the cultivation of optimum seedlings, while promoting the growth of trees (Hua, 1995).

Mycorrhizal fungi are important for trees, such as Eucalyptus and Populus, and they can improve the growth and stress resistance of trees (Lapeyrie \& Chilvers, 1985; Lodge \& Wentworth, 1990; Tan et al., 2000). Eucalyptus is a typical mycorrhizal nutritional plant, it has ectomycorrhiza, endomycorrhiza and dual mycorrhiza (Chen et al., 1998; Tan et al., 2000), and research has shown that inoculation with mycorrhizal fungi can positively affect Eucalyptus tree species; thus, it has evolved as a key technique toward matching tree species with mycorrhizal fungi in certain regions (Gong et al., 1997; Zhong et al., 2001). Currently, investigations into the effects of mycorrhizal fungi inoculation on Eucalyptus globulus, Eucalyptus urophylla, Eucalyptus grandis $\times$ E.urophylla, and other species of Eucalyptus have been conducted (Wang et al., 2003; Huang et al., 2008). However, investigations into the inoculation of endomycorrhizal fungi on E. maidenii in Yunnan, China have not been conducted as yet.

For this study, bulk soil was collected from an $E$. maidenii plantation at the Jindian tree farm in Kunming City, Yunnan Province. Endomycorrhizal fungi in the bulk soil were isolated, identified, and counted, whereafter the overall and dominant species were investigated. The effects of endomycorrhizal fungi on the growth indices and nutrient characteristics of the E. maidenii seedlings were analyzed via a single factor experimental design, where the populations of endomycorrhizal fungi in the seedling substrate were controlled.

The primary endomycorrhizal fungal species that facilitated growth promotion and nutrient absorption for E. maidenii seedlings were ascertained via stepwise regression analysis. The main objectives of this study were to: (1) isolate and identify the overall and dominant species of endomycorrhizal fungi on E. maidenii in Yunnan Province, (2) elucidate the effect of endomycorrhizal fungi on E. maidenii seedlings via a single factor experimental design, and (3) determine the primary endomycorrhizal fungi species on the E. maidenii seedlings via stepwise regression analysis. This study provides a theoretical basis and practical guidance for the optimal cultivation of E. maidenii seedlings. The issues of soil degradation and the decline of forest productivity in E. maidenii plantations might be resolved through the use of mycorrhizal seedlings as afforestation materials.

\section{Methods}

\section{Jindian tree farm profiles}

Jindian tree farm is located in the northeast of kunming City, Yunnan Province, and in north latitude 27 degrees 7 minutes and east longitude 102 degrees 43 minutes. The altitude of Jindian tree farm is $1,900-2,338$ meters, the slope is $10-30$ degrees, and the soil type is mountainous forest red soil. Jindian tree farm is located in the subtropical climate zone of China. Pinus yunnanensis natural forest, E. maidenii plantation, Pinus armandii plantation, and Acacia mearnsii plantation are distributed in Jindian tree farm, it is an important ecological protection barrier for kunming City. The land of E. maidenii plantation was ever colonized by $P$. yunnanensis natural forest, then the native forest was cut down to grow E. maidenii. E. maidenii plantation is managed as an ecological forest, thus it has not being rotational felled, the trees of E. maidenii plantation are $23 \mathrm{yr}$ old. Currently, investigations into the species of mycorrhizal fungi and the effects of mycorrhizal fungi inoculation on the trees in Jindian tree farm have not been conducted as yet.

\section{Bulk soil collection}

The bulk soil collection zone was located at the E. maidenii plantation of Jindian tree farm. In April 2018, thirty E. maidenii samples were selected in the plantation for the extraction of bulk soil. In the canopy projection zone of each tree, about $1 \mathrm{~m}$ from the trunk of the tree, approximately $500 \mathrm{~g}$ bulk soil and fibrous roots were collected from each direction (i.e., east, south, west, and north), well mixed, and then placed into bags. Subsequently the bulk soil of each tree was taken back to the nursery, well mixed, and used for isolating endomycorrhizal fungi and cultivating seedlings.

\section{Isolation and identification of endomycorrhizal fungi}

The endomycorrhizal fungi spores were isolated by the wet sieve method (Trappe \& Schenck, 1982; 
Zhu et al., 2001a). Using glycerine as the suspending agent and glass slides as carriers, the spores of endomycorrhizal fungi were observed under a microscope (Nikon YS100) $(\times 400)$. The endomycorrhizal fungi spores were identified according to their morphological characteristics (i.e., size, color, spore wall layers, thickness, spore inclusions) (Schenck \& Perez, 1988; An et al., 1990; Redecker et al., 2013).

\section{Counting of endomycorrhizal fungi spores}

Five grams of bulk soil was weighed, after which the resident endomycorrhizal fungi spores were isolated by the wet sieve method (Trappe \& Schenck, 1982; Zhu et al., 2001a). Subsequently, the spores were counted under an anatomical lens (Nikon SMZ1500) $(\times 10)$, and the experiment was repeated three times.

$$
\begin{aligned}
& \text { Spore density }(\mathrm{pcs} / \mathrm{g})=\text { the number of spores/ } \\
& \text { the weight of bulk soil }
\end{aligned}
$$

\section{Cultivation of Eucalyptus maidenii seedlings}

E. maidenii seedlings were cultivated in the permanent nursery of Southwest Forestry University in Kunming City, China. The seedlings were cultivated outdoors in full sun, the max, min, and mean temperatures were $30.3^{\circ} \mathrm{C}, 2^{\circ} \mathrm{C}$, and $15.7^{\circ} \mathrm{C}$ respectively duration of the experiment. The E. maidenii seeds were obtained from the Forest Seed and Seedling Station of Yunnan Province. The container seedlings of $E$. maidenii were cultivated via a single factor experiment, which was designed to include three experimental treatments. For the three experimental treatments, the weight of soil substrate per container was consistent at $1.5 \mathrm{~kg}$. For the first experimental treatment, the seedling substrate was comprised of bulk soil that was sterilized at $121{ }^{\circ} \mathrm{C}$ for two hours, where the percentage of endomycorrhizal fungi was 0 . For the second experimental treatment, the seedling substrate was comprised of bulk soil, half of which was sterilized at $121^{\circ} \mathrm{C}$ for two hours, and half was not, where the percentage of endomycorrhizal fungi was $50 \%$. For the third experimental treatment, the seedling substrate was comprised of bulk soil that was not sterilized, where the percentage of endomycorrhizal fungi was $100 \%$. This experiment was designed by a random arrangement in the field, in triplicate, with thirty seedlings for each repetition. The seedling cultivation began in May 2018 and was concluded in March 2019. The containers of three experimental treatments were not fertilized at all over the experimental period, and were watered with equal quantity duration of the experiment.

\section{Infection rate of endomycorrhizal fungi}

At the completion of the experiment in March 2019, three seedlings were randomly selected to study the infection rate of endomycorrhizal fungi in each experimental treatment. The intact roots of the seedlings were dug out, after which the seedling substrate on the roots were gently washed off. The roots were then cut into several segments $(\sim 1 \mathrm{~cm}$ long), and placed into a FAA (Formalin-acetic acid-alcohol) fixative solution for $24 \mathrm{~h}$. Afterwards, the roots were immersed in a $10 \% \mathrm{KOH}$ solution and then a water bath at $90{ }^{\circ} \mathrm{C}$ for $1 \mathrm{~h}$. Subsequently, the roots were introduced into a $10 \% \mathrm{H}_{2} \mathrm{O}_{2}$ solution at room temperature for $20 \mathrm{~min}$. The roots were then placed into a $1 \% \mathrm{HCl}$ solution for $5 \mathrm{~min}$, and then a $0.05 \%$ aniline blue solution, and water bath at $90{ }^{\circ} \mathrm{C}$ for 35 min for staining.

The roots were then soaked in lactic acid glycerol to remove any excess aniline blue, and used in the preparation of a glass slide (Berch \& Kendrick, 1982; Schenck \& Perez, 1988; Wu et al., 2014). The roots were observed under a microscope (Nikon YS100) $(\times 400)$, where the infection rate and intensity were calculated (Nicolson \& Schenck, 1979; Li \& Feng, 2001). According to the proportion of the number of root segments being infected to the number of root segments being observed, the infection intensities were distinguished by five grades (i.e., $0-5 \%$ for grade I, $6-25 \%$ for grade II, $26-50 \%$ for grade III, $51-75 \%$ for grade IV, and $76-100 \%$ for grade V).

Infection rate $(\%)=$ (the length of root segments being infected/the length of root segments being observed) $\times 100 \%$

\section{Determination of the growth and nutrient indices of Eucalyptus maidenii seedlings}

At the completion of the experiment in March 2019, the seedling heights, stem diameters at ground level, dry matter weight (i.e., roots, stems, and leaves), and the number of primary and secondary lateral roots of the seedlings being cultivated under the three experimental treatments were measured. The experiments were conducted in triplicate, with thirty seedlings per repetition for the seedling heights, stem diameters at ground level, and the number of primary and secondary lateral roots, with twenty-seven seedlings per repetition for the dry matter weight (i.e., roots, stems, and leaves). 
Three seedlings were randomly selected for each experimental treatment, and the roots of each seedling were weighed to $0.5 \mathrm{~g}$ for determining the root activity via the TTC (triphenyl tetrazolium chloride) method (Li, 2000). Briefly, this involved the reduction amount of TTC to reflect the activity of dehydrogenase in roots, and then explain the root activity. Subsequently, the roots, stems, and leaves of the seedlings were grinded, respectively, meanwhile the seedling substrate of each experimental treatment were grinded, respectively. The experiment was designed to be conducted in triplicate, after which the concentrations of total nitrogen (Kjeldahl method), total phosphorus (molybdenum antimony colorimetric method), total potassium (flame photometer), available phosphorus (sodium bicarbonate extraction - molybdenum antimony colorimetric method), available potassium (ammonium acetate extraction - flame photometer), and alkalitic nitrogen (alkali $\mathrm{N}$-proliferation method) in the seedling samples and nursery substrates were determined, respectively $(\mathrm{Li}$, 2000).

\section{Screening of major endomycorrhizal fungi species for their effect on the growth and nutrient indices of Eucalyptus maidenii seedlings}

Correlation analyses were performed on the growth, biomass, root activity, and nutrient concentration of 11-month-old E. maidenii seedlings, with the species of endomycorrhizal fungi being identified in this study, respectively. According to the results of the correlation analyses, stepwise regression analyses were performed to establish regression equations, respectively. Based on the results of the correlation and stepwise regression analyses, the major species of endomycorrhizal fungi involved with the growth and nutrient absorption of the E. maidenii seedlings were ascertained. The data analyses were implemented by SPSS17.0 and Excel2007.

\section{Results}

\section{Species of endomycorrhizal fungi in the Eucalyptus maidenii plantation}

Five species of arbuscular endomycorrhizal fungi were isolated from the bulk soil of E. maidenii, which were derived from three genera (i.e., Glomus, Claroideoglomus, and Septoglomus) (Table 1). The morphological characteristics of the spores of these five species of endomycorrhizal fungi are shown in Fig. 1. Among the five species of endomycorrhizal fungi, the spore densities of G. mosseae and G. aggregatum were higher
Table 1. Species and spore density of endomycorrhizal fungi in the bulk soil of Eucalyptus maidenii

\begin{tabular}{llc}
\hline \multicolumn{1}{c}{ Genus } & \multicolumn{1}{c}{ Species } & $\begin{array}{c}\text { Spore density of } \\
\text { endomycorrhizal } \\
\text { fungi (pcs/g) }\end{array}$ \\
\hline Glomus & Glomus mosseae & 32 \\
& Glomus multicaule & 10 \\
Claroideoglomus & Glomus aggregatum & 24 \\
Septoglomus & Septoglomus constrictum & 13 \\
\hline
\end{tabular}

than those of the others (Table 1). Furthermore, the ratio of the spore density of G. mosseae to that of the other five species of endomycorrhizal fungi was $37.65 \%$, whereas the ratio of the spore density of $G$. aggregatum to that of the other five species of endomycorrhizal fungi was $28.24 \%$, giving a sum total of $65.89 \%$. Therefore, it was considered that G. mosseae and G. aggregatum were the dominant species of endomycorrhizal fungi in the bulk soil of E. maidenii.

\section{Endomycorrhizal infection of the Eucalyptus maidenii seedlings}

In March 2019, the results of the endomycorrhizal infection rate and intensity of the seedlings of E. maidenii (Table 2) revealed that the endomycorrhiza fungi were formed on the roots of all seedlings of E. maidenii in the second and third experimental treatments. Furthermore, with the increased number of endomycorrhizal fungi spores in the seedling substrate, both the infection rate and intensity of the seedlings increased.

Table 2. Endomycorrhizal infection rate and intensity of the Eucalyptus maidenii seedlings by cultivating with different soil treatments

\begin{tabular}{ccc}
\hline $\begin{array}{c}\text { Experimental } \\
\text { treatment }\end{array}$ & $\begin{array}{c}\text { Endomycorrhizal } \\
\text { infection rate (\%) }\end{array}$ & $\begin{array}{c}\text { Endomycorrhizal } \\
\text { infection intensity }\end{array}$ \\
\hline 1 & 0 & 0 \\
2 & 63.2 & IV \\
3 & 93.5 & $\mathrm{~V}$ \\
\hline
\end{tabular}

\section{Effects of different soil treatments on the growth indices and root activities of the Eucalyptus maidenii seedlings}

The results of the growth indices and root activities of the E. maidenii seedlings by culturing with different soil treatments (Table 3) revealed that the seedling height, stem diameter, dry weights of roots, stems, and leaves, root-shoot ratio, number of primary lateral roots, number of secondary lateral roots, and root activity all increased with the higher number of endomycorrhizal fungi spores in 

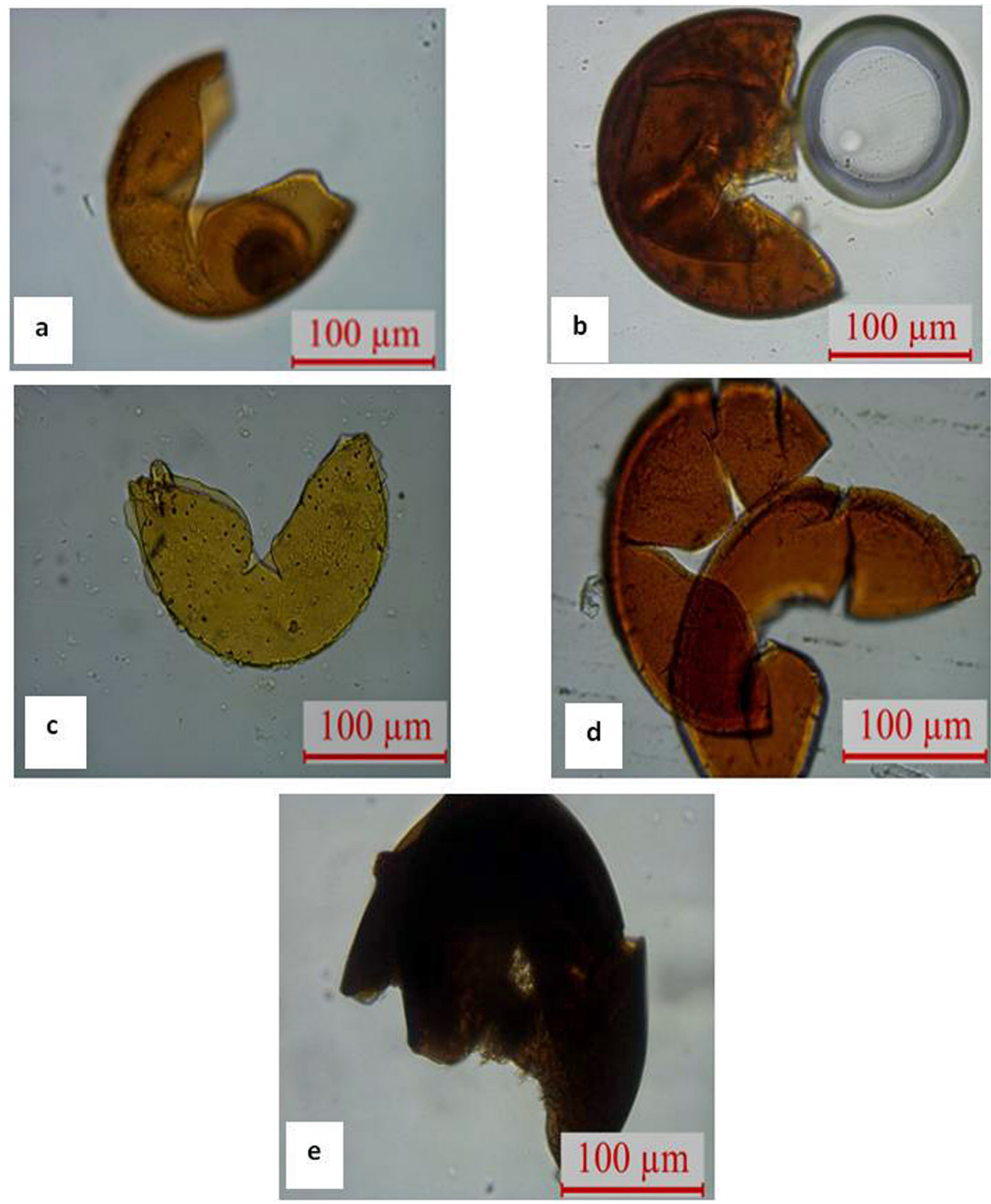

Fig. 1. Morphological characteristics of the endomycorrhizal fungi spores in bulk soil of Eucalyptus maidenii ( $\times 400)$ (a. Glomus mosseae; b. Glomus multicaule; c. Glomus aggregatum; d. Claroideoglomus etunicatum; e.Septoglomus constrictum)

Table 3 Effects of different soil treatments on the growth indices and the root activities of Eucalyptus maidenii seedlings

\begin{tabular}{cccccccccc}
\hline $\begin{array}{c}\text { Experi- } \\
\text { mental } \\
\text { treat- } \\
\text { ment }\end{array}$ & $\begin{array}{c}\text { Seedling } \\
\text { height }(\mathrm{cm})\end{array}$ & $\begin{array}{c}\text { Stem } \\
\text { diameter } \\
(\mathrm{mm})\end{array}$ & $\begin{array}{c}\text { Root dry } \\
\text { weight } \\
(\mathrm{g})\end{array}$ & $\begin{array}{c}\text { Stem dry } \\
\text { weight } \\
(\mathrm{g})\end{array}$ & $\begin{array}{c}\text { Leaf dry } \\
\text { weight } \\
(\mathrm{g})\end{array}$ & $\begin{array}{c}\text { Root-shoot } \\
\text { ratio }\end{array}$ & $\begin{array}{c}\text { Number of } \\
\text { first order } \\
\text { lateral roots } \\
(\mathrm{stick})\end{array}$ & $\begin{array}{c}\text { Number of } \\
\text { second order } \\
\text { lateral roots } \\
(\mathrm{stick})\end{array}$ & $\begin{array}{c}\text { Root activity } \\
(\mu \mathrm{g} / \mathrm{g} / \mathrm{h})\end{array}$ \\
\hline 1 & $32.92 \pm 8.70 \mathrm{~b}$ & $2.42 \pm 0.75 \mathrm{a}$ & $0.26 \pm 0.08 \mathrm{~b}$ & $0.73 \pm 0.25 \mathrm{a}$ & $0.63 \pm 0.01 \mathrm{a}$ & $0.20 \pm 0.31 \mathrm{~b}$ & $38.22 \pm 8.18 \mathrm{a}$ & $398.11 \pm 85.59 \mathrm{~b}$ & $450.89 \pm 81.16 \mathrm{~b}$ \\
2 & $37.31 \pm 3.28 \mathrm{ab}$ & $2.43 \pm 0.33 \mathrm{a}$ & $0.36 \pm 0.11 \mathrm{~b}$ & $0.81 \pm 0.24 \mathrm{a}$ & $0.69 \pm 0.27 \mathrm{a}$ & $0.24 \pm 0.04 \mathrm{ab}$ & $40.78 \pm 8.35 \mathrm{a}$ & $404.44 \pm 121.08 \mathrm{~b}$ & $566.44 \pm 72.60 \mathrm{~b}$ \\
3 & $43.39 \pm 3.62 \mathrm{a}$ & $3.06 \pm 0.75 \mathrm{a}$ & $0.51 \pm 0.16 \mathrm{a}$ & $1.01 \pm 0.28 \mathrm{a}$ & $0.88 \pm 0.35 \mathrm{a}$ & $0.27 \pm 0.05 \mathrm{a}$ & $47.00 \pm 9.37 \mathrm{a}$ & $543.67 \pm 12.47 \mathrm{a}$ & $758.67 \pm 313.42 \mathrm{a}$ \\
\hline
\end{tabular}

Note: Lowercase letters indicate significant difference at 0.05 level. 
the seedling substrate. For the seedling height, there were significant differences between the three experimental treatments $(\mathrm{P}=0.031)$. The seedling height of the third experimental treatment was significantly greater than that of the first experimental treatment, whereas the seedling height of the second experimental treatment was the transition group. The results of the variance analysis and multiple comparisons of the root-shoot ratio $(\mathrm{P}=0.038)$ were similar to that of the seedling height.

For the dry weight of roots, there were significant differences between the three experimental treatments $(\mathrm{P}=0.017)$, where that of the third experimental treatment was significantly greater than the first and second experimental treatments, while there was no significant difference between the first and second experimental treatments. The results of the variance analysis and multiple comparisons of the number of secondary lateral roots $(\mathrm{P}=0.024)$ and root activities $(\mathrm{P}=0.015)$ were similar to that of the dry weight of roots.

For the stem diameter, the dry weight of stems, the dry weight of leaves, and the number of primary lateral roots, there were no significant differences between the three experimental treatments (all were $\mathrm{P}>0.05)$. Above all, the seedling roots, particularly the number of secondary lateral roots and the root activities were significantly promoted by the third experimental treatment. It was revealed that the major indices of the absorption capacity of roots were enhanced when a certain number of endomycorrhizal fungi spores were added to the seedling substrate for the cultivation of the E. maidenii seedlings.

\section{Effects of different soil treatments on the nutrient concentration in the bulk soil of the Eucalyptus maidenii seedlings}

The results of the nutrient concentration in the bulk soil of the E. maidenii seedlings obtained through culturing with different soil treatments (Table 4) indicated that the concentrations of total nitrogen, total phosphorus, available nitrogen, available phosphorus, and available potassium increased with the higher number of endomycorrhizal fungi spores in the seedling substrate. Initially, the concentration of total potassium increased and then decreased, whereas for the total nitrogen, the total phosphorus, the total potassium, the available nitrogen and the available potassium, there were significant differences between three experimental treatments (all were $\mathrm{P}<0.05$ ), while there was no significant difference between three experimental treatments for the available phosphorus $(\mathrm{P}=0.154)$.

The results of the variance analysis and multiple comparisons of the total nitrogen, total phosphorus, and available potassium of the third experimental treatment were significantly greater than that of the first experimental treatment (all were $\mathrm{P}<0.05$ ). The total nitrogen, total phosphorus, and available potassium of the second experimental treatment was the transition group. The results of the variance analysis and multiple comparisons of the available nitrogen of the second and third experimental treatments were significantly larger than that of the first experimental treatment (all were $\mathrm{P}<0.05$ ), and there was no significant difference for the available nitrogen between the second and third experimental treatments $(\mathrm{P}=0.079)$.

The results of the variance analysis and multiple comparisons of the total potassium of the second experimental treatment were significantly larger than that of the first experimental treatment $(\mathrm{P}=0.042)$, and the total potassium of the third experimental treatment was the transition group. In summary, the concentrations of nitrogen, phosphorus, and potassium in the bulk soil of the E. maidenii seedlings increased significantly for the third experimental treatment. It was shown that the concentrations of the major nutrients in the bulk soil for the growth of seedlings were improved when a certain number of spores of endomycorrhizal fungi was added to the seedling substrate.

\section{Effects of different soil treatments on the nutrient concentration of Eucalyptus maidenii seedlings}

The results of investigations into the nutrient concentration of different organs (i.e., roots, stems, and leaves) of E. maidenii seedlings by culturing with different soil treatments (Table 5) revealed that the concentration of nitrogen in roots, stems, and leaves; phosphorus in stems and leaves; and potassium in

Table 4. Effects of the different soil treatments on the nutrient concentration of the bulk soil of the Eucalyptus maidenii seedlings

\begin{tabular}{ccccccc}
\hline $\begin{array}{c}\text { Experimental } \\
\text { treatment }\end{array}$ & $\begin{array}{c}\text { Total nitrogen } \\
(\mathrm{g} / \mathrm{kg})\end{array}$ & $\begin{array}{c}\text { Total phosphorus } \\
(\mathrm{g} / \mathrm{kg})\end{array}$ & $\begin{array}{c}\text { Total potassium } \\
(\mathrm{g} / \mathrm{kg})\end{array}$ & $\begin{array}{c}\text { Available nitro- } \\
\text { gen }(\mathrm{mg} / \mathrm{kg})\end{array}$ & $\begin{array}{c}\text { Available phos- } \\
\text { phorus }(\mathrm{mg} / \mathrm{kg})\end{array}$ & $\begin{array}{c}\text { Available potassi- } \\
\mathrm{um}(\mathrm{mg} / \mathrm{kg})\end{array}$ \\
\hline 1 & $1.22 \pm 0.17 \mathrm{~b}$ & $0.10 \pm 0.02 \mathrm{~b}$ & $2.65 \pm 0.19 \mathrm{~b}$ & $46.93 \pm 3.49 \mathrm{~b}$ & $4.36 \pm 1.99 \mathrm{a}$ & $65.98 \pm 4.80 \mathrm{~b}$ \\
2 & $1.33 \pm 0.12 \mathrm{ab}$ & $0.12 \pm 0.04 \mathrm{ab}$ & $3.16 \pm 0.29 \mathrm{a}$ & $50.31 \pm 1.37 \mathrm{a}$ & $4.56 \pm 0.95 \mathrm{a}$ & $68.13 \pm 3.87 \mathrm{ab}$ \\
3 & $1.45 \pm 0.14 \mathrm{a}$ & $0.16 \pm 0.05 \mathrm{a}$ & $2.88 \pm 0.41 \mathrm{ab}$ & $51.89 \pm 2.16 \mathrm{a}$ & $5.34 \pm 1.01 \mathrm{a}$ & $78.45 \pm 19.46 \mathrm{a}$ \\
\hline
\end{tabular}

Note: Lowercase letters indicate significant difference at 0.05 level. 
Table 5. Effects of the different soil treatments on the nutrient concentration of the Eucalyptus maidenii seedlings

\begin{tabular}{|c|c|c|c|c|c|c|c|c|c|}
\hline \multirow{2}{*}{$\begin{array}{c}\text { Experi- } \\
\text { mental } \\
\text { treatment }\end{array}$} & \multicolumn{3}{|c|}{ Nitrogen $(\mathrm{g} / \mathrm{kg})$} & \multicolumn{3}{|c|}{ Phosphorus (g/kg) } & \multicolumn{3}{|c|}{ Potassium $(\mathrm{g} / \mathrm{kg})$} \\
\hline & Root & Stem & Leaf & Root & Stem & Leaf & Root & Stem & Leaf \\
\hline 1 & $1.39 \pm 0.41 b$ & $1.31 \pm 0.22 b$ & $1.44 \pm 0.36 b$ & $0.17 \pm 0.03 b$ & $0.11 \pm 0.22 b$ & $0.42 \pm 0.16 \mathrm{~b}$ & $2.30 \pm 0.33 a$ & $1.27 \pm 0.39 \mathrm{a}$ & $2.43 \pm 0.54 a$ \\
\hline 2 & $1.54 \pm 0.28 b$ & $1.47 \pm 0.25 b$ & $1.59 \pm 0.31 b$ & $0.30 \pm 0.06 \mathrm{a}$ & $0.18 \pm 0.07 a b$ & $0.45 \pm 0.08 b$ & $2.47 \pm 0.42 \mathrm{a}$ & $1.29 \pm 0.33 a$ & $2.36 \pm 0.46 \mathrm{a}$ \\
\hline 3 & $2.17 \pm 0.21 \mathrm{a}$ & $2.02 \pm 0.39 \mathrm{a}$ & $1.76 \pm 0.28 \mathrm{a}$ & $0.26 \pm 0.06 \mathrm{a}$ & $0.20 \pm 0.09 a$ & $0.61 \pm 0.26 \mathrm{a}$ & $2.48 \pm 0.34 \mathrm{a}$ & $1.26 \pm 0.20 \mathrm{a}$ & $2.19 \pm 0.30 \mathrm{a}$ \\
\hline
\end{tabular}

Note: Lowercase letters indicate significant difference at 0.05 level.

roots were increased with the higher number of endomycorrhizal fungi spores in the seedling substrate. Interestingly, the concentrations of phosphorus in roots and potassium in stems initially increased and then decreased. For the concentration of potassium in roots, stems, and leaves, there were no significant differences between the three experimental treatments (all were $\mathrm{P}>0.05$ ).

The concentration of nitrogen in roots, stems, and leaves, were significantly different between the three experimental treatments (all were $\mathrm{P}<0.05$ ). The results of multiple comparisons for the indices of the third experimental treatment were significantly greater than that of the first and second experimental treatments (all were $\mathrm{P}<0.05$ ), and there was no significant difference for these indices between the first and second experimental treatments $(\mathrm{P}=0.283)$.

The concentration of phosphorus in roots, stems, and leaves, were significantly different between the three experimental treatments (all were $\mathrm{P}<0.05$ ). Furthermore, the results of the multiple comparisons for the indices of the third experimental treatment were significantly greater than that of the first experimental treatment. From the above, the concentrations of nitrogen, phosphorus, and potassium in the roots, stems, and leaves of the seedlings increased significantly via the third experimental treatment. This signified that the concentrations of the major nutrients in the seedlings were enhanced when a certain number of endomycorrhizal fungi spores was added to the seedling substrate.

\section{Correlation analysis of the nutrient concentration in the bulk soil and seedlings of Eucalyptus maidenii}

Correlation analysis of the nutrient concentration in the bulk soil and seedlings of E. maidenii was performed (Table 6). The concentration of nitrogen in the aerial components of seedlings (i.e., stems and leaves) had a significantly positive correlation with the concentration of nitrogen (i.e., total nitrogen and available nitrogen) in the bulk soil. The concentration of nitrogen in the stems and roots of seedlings exhibited a significantly positive correlation with the concentrations of total phosphorus and available phosphorus in the bulk soil, respectively. The concentration of phosphorus in the roots of seedlings had a significantly positive correlation with the concentrations of available nitrogen and total potassium in the bulk soil, respectively. To summarize, the concentrations of nutrients in the E. maidenii seedlings were significantly positively correlated with those in the bulk soil.

\section{Correlation analysis of the growth indices and nutrient concentration of the Eucalyptus maidenii seedlings}

Correlation analysis of the growth indices with the concentrations of nutrients of the E. maidenii seedlings was performed (Table 7). The seedling height

Table 6. Correlation of the nutrient concentration in the bulk soil and seedlings of Eucalyptus maiden

\begin{tabular}{|c|c|c|c|c|c|c|c|}
\hline $\begin{array}{l}\text { Nutrients } \\
\text { in seedlings }\end{array}$ & $\begin{array}{r}\text { Nutrients in } \\
\text { rhizosphere soil }\end{array}$ & $\begin{array}{c}\text { Total nitrogen } \\
\text { of bulk soil }\end{array}$ & $\begin{array}{l}\text { Total phospho- } \\
\text { rus of bulk soil }\end{array}$ & $\begin{array}{l}\text { Total potassi- } \\
\text { um of bulk soil }\end{array}$ & $\begin{array}{l}\text { Available nitro- } \\
\text { gen of bulk soil }\end{array}$ & $\begin{array}{c}\text { Available } \\
\text { phosphorus of } \\
\text { bulk soil }\end{array}$ & $\begin{array}{c}\text { Available } \\
\text { potassium of } \\
\text { bulk soil }\end{array}$ \\
\hline \multirow[t]{3}{*}{ Root } & Nitrogen & 0.271 & 0.220 & 0.059 & 0.344 & $0.587^{* *}$ & -0.080 \\
\hline & Phosphorus & 0.210 & 0.071 & $0.460^{*}$ & $0.427^{*}$ & -0.041 & -0.253 \\
\hline & Potassium & 0.320 & -0.064 & 0.088 & 0.026 & -0.100 & -0.296 \\
\hline \multirow[t]{3}{*}{ Stem } & Nitrogen & $0.396^{*}$ & $0.424^{*}$ & 0.097 & $0.563^{* *}$ & 0.261 & -0.292 \\
\hline & Phosphorus & 0.052 & 0.331 & 0.319 & 0.242 & 0.038 & -0.266 \\
\hline & Potassium & 0.059 & 0.136 & 0.070 & -0.231 & 0.096 & -0.072 \\
\hline \multirow[t]{3}{*}{ Leaf } & Nitrogen & 0.316 & 0.065 & 0.222 & $0.424^{*}$ & -0.118 & -0.127 \\
\hline & Phosphorus & 0.044 & 0.226 & 0.060 & 0.104 & 0.192 & -0.270 \\
\hline & Potassium & -0.112 & -0.143 & 0.018 & 0.072 & -0.236 & 0.027 \\
\hline
\end{tabular}

Note: “**” indicates significant correlation at 0.01 level; “*” indicates significant correlation at 0.05 level. 
Table 7. Correlation of the growth and the nutrient concentration of the Eucalyptus maidenii seedlings

\begin{tabular}{|c|c|c|c|c|c|c|c|c|c|}
\hline \multicolumn{2}{|c|}{ Nutrients in seedlings } & $\begin{array}{c}\text { Seedling } \\
\text { height }\end{array}$ & $\begin{array}{c}\text { Stem } \\
\text { diameter }\end{array}$ & $\begin{array}{c}\text { Number } \\
\text { of first } \\
\text { order } \\
\text { lateral } \\
\text { roots }\end{array}$ & $\begin{array}{l}\text { Number } \\
\text { of second } \\
\text { order } \\
\text { lateral } \\
\text { roots }\end{array}$ & $\begin{array}{l}\text { Root } \\
\text { activity }\end{array}$ & $\begin{array}{l}\text { Root dry } \\
\text { weight }\end{array}$ & $\begin{array}{l}\text { Stem dry } \\
\text { weight }\end{array}$ & $\begin{array}{l}\text { Leaf dry } \\
\text { weight }\end{array}$ \\
\hline \multirow[t]{3}{*}{ Root } & Nitrogen & $0.573^{* *}$ & $0.504^{* *}$ & 0.216 & $0.521^{* *}$ & $0.530^{* *}$ & $0.539^{* *}$ & 0.227 & 0.301 \\
\hline & Phosphorus & 0.310 & 0.231 & 0.220 & -0.117 & $0.454^{*}$ & 0.295 & 0.138 & 0.202 \\
\hline & Potassium & -0.182 & -0.048 & -0.012 & -0.015 & 0.143 & 0.215 & 0.090 & 0.066 \\
\hline \multirow[t]{3}{*}{ Stem } & Nitrogen & $0.518^{* *}$ & 0.109 & 0.158 & 0.362 & 0.163 & $0.417^{*}$ & 0.261 & 0.194 \\
\hline & Phosphorus & 0.330 & 0.362 & $0.428^{*}$ & 0.287 & $0.534^{* *}$ & $0.475^{*}$ & 0.337 & 0.361 \\
\hline & Potassium & -0.226 & -0.149 & -0.019 & -0.313 & 0.117 & -0.005 & -0.066 & 0.000 \\
\hline \multirow[t]{3}{*}{ Leaf } & Nitrogen & 0.246 & 0.201 & 0.073 & 0.181 & 0.071 & 0.171 & 0.186 & 0.152 \\
\hline & Phosphorus & 0.235 & -0.242 & 0.320 & $0.531^{* *}$ & $0.664^{* *}$ & 0.262 & -0.053 & -0.017 \\
\hline & Potassium & -0.227 & -0.242 & -0.044 & -0.210 & -0.186 & -0.236 & -0.087 & -0.154 \\
\hline
\end{tabular}

Note: “**” indicates significant correlation at 0.01 level; “*” indicates significant correlation at 0.05 level.

was significantly positively correlated to the concentration of nitrogen in roots and stems, respectively. The stem diameter had significantly positive correlation with the concentration of nitrogen in roots. The root activity was significantly positively correlated to the concentration of nitrogen in roots, and the concentration of phosphorus in stems, leaves, and roots, respectively.

The number of lateral roots was significantly positively correlated with the concentration of phosphorus in the aerial components of seedlings (i.e., stems and leaves) and the concentration of nitrogen in roots. Overall, the growth indices of the aerial components of seedlings had a significantly positive correlation with the concentration of nitrogen in the seedlings. Meanwhile the capacity of nutrient absorption (i.e., root activity and the number of lateral roots) was significantly positively correlated with the concentration of phosphorus of seedlings and the concentration of nitrogen in roots, respectively.

Table 8. Stepwise regression analysis between the five species of endomycorrhizal fungi and their growth indices for the Eucalyptus maidenii seedlings

\begin{tabular}{lcccc}
\hline \multicolumn{1}{c}{ Indexes } & Regression equation & $\begin{array}{c}\text { Correlation } \\
\text { coefficient }\end{array}$ & $\begin{array}{c}\text { Fitting coeffi- } \\
\text { cient }\end{array}$ & Significance \\
\hline Seedling height & $\mathrm{y}=30.841+0.299 \mathrm{X}_{1}+1.792 \mathrm{X}_{4}$ & 0.78 & 0.608 & 0.060 \\
Stem diameter & - & - & - & - \\
Dry weight of root & $\mathrm{y}=0.293+0.010 \mathrm{X}_{3}$ & 0.676 & 0.457 & $0.046^{*}$ \\
Dry weight of stem & - & - & - & - \\
Dry weight of leaf & - & - & - & 0.147 \\
Total biomass (dry weight) & $\mathrm{y}=1.571+0.182 \mathrm{X}_{4}$ & 0.524 & 0.275 & $0.016^{*}$ \\
Root shoot ratio & $\mathrm{y}=0.192+0.008 \mathrm{X}_{2}+0.002 \mathrm{X}_{4}$ & 0.866 & 0.75 & $0.001^{* *}$ \\
Number of first order lateral roots & $\mathrm{y}=37.943+1.299 \mathrm{X}_{2}$ & 0.891 & 0.793 & $0.003^{* *}$ \\
Number of second order lateral roots & $\mathrm{y}=382.690+21.155 \mathrm{X}_{2}$ & 0.854 & 0.73 & $0.012^{*}$ \\
Root activity & $\mathrm{y}=419.571+10.238 \mathrm{X}_{1}+7.820 \mathrm{X}_{3}$ & 0.879 & 0.722 & $0.002^{* *}$ \\
Nitrogen concentration of root & $\mathrm{y}=1.165+0.135 \mathrm{X}_{2}+0.182 \mathrm{X}_{4}-0.027 \mathrm{X}_{1}$ & 0.97 & 0.941 & $0.006^{* *}$ \\
Phosphorus concentration of root & $\mathrm{y}=0.149+0.031 \mathrm{X}_{4}+0.003 \mathrm{X}_{1}$ & 0.902 & 0.814 & 0.099 \\
Potassium concentration of root & $\mathrm{y}=2.318+0.032 \mathrm{X}_{2}$ & 0.584 & 0.341 & $0.029^{*}$ \\
Nitrogen concentration of stem & $\mathrm{y}=1.295+0.029 \mathrm{X}_{1}$ & 0.722 & 0.521 & $0.004^{* *}$ \\
Phosphorus concentration of stem & $\mathrm{y}=0.106+0.004 \mathrm{X}_{1}+0.003 \mathrm{X}_{3}$ & 0.916 & 0.838 & - \\
Potassium concentration of stem & - & - & - & 0.055 \\
Nitrogen concentration of leaf & $\mathrm{y}=1.374+0.102 \mathrm{X}_{4}$ & 0.656 & 0.430 \\
Phosphorus concentration of leaf & $\mathrm{y}=0.422+0.023 \mathrm{X}_{2}$ & 0.722 & 0.521 & $0.028^{*}$ \\
Potassium concentration of leaf & - & - & - & - \\
Total nitrogen concentration of bulk soil & $\mathrm{y}=1.207+0.012 \mathrm{X}_{2+} 0.011 \mathrm{X}_{3}$ & 0.952 & 0.905 & $0.001^{* *}$ \\
Total phosphorus concentration of bulk soil & $\mathrm{y}=0.094+0.015 \mathrm{X}_{4}$ & 0.585 & 0.342 & 0.098 \\
Total potassium concentration of bulk soil & - & - & - & - \\
Available nitrogen concentration of bulk soil & $\mathrm{y}=47.581+0.202 \mathrm{X}_{1}$ & 0.630 & 0.397 & 0.069 \\
Available phosphorus concentration of bulk soil & $\mathrm{y}=4.310+0.142 \mathrm{X}_{2}$ & 0.538 & 0.290 \\
Available potassium concentration of bulk soil & - & - & - & 0.135 \\
\hline
\end{tabular}

Note: $\mathrm{X}_{1}$ - Glomus mosseae, $\mathrm{X}_{2}$ - Glomus multicaule, $\mathrm{X}_{3}-$ Glomus aggregatum, $\mathrm{X}_{4}$ - Claroideoglomus etunicatum, $\mathrm{X}_{5}-$ Septoglomus constrictum, “**” indicates significant correlation at 0.01 level; “*” indicates significant correlation at 0.05 level. 


\section{Screening of the major species of endomycorrhizal fungi for the Eucalyptus maidenii seedlings}

Regression equations were developed between the five species of endomycorrhizal fungi and each index (i.e., dry weight of roots, root-shoot ratio, number of lateral roots, root activity, concentrations of nitrogen and phosphorus in roots and stems, phosphorus in leaves, and total nitrogen in bulk soil). Furthermore, the five species of endomycorrhizal fungi were significantly linearly correlated with each index (Table 8). By exploiting stepwise regression, we identified the main species of endomycorrhizal fungi that affected the nutrient concentration and growth of E. maidenii seedlings, which were G. multicaule, G. aggregatum, and C. etunicatum (Table 8).

\section{Discussion}

\section{Endomycorrhizal fungi species in the bulk soil of Eucalyptus maidenii plantation}

In this study, five species of endomycorrhizal fungi were isolated from the bulk soil of an E. maidenii plantation in Kunming City, Yunnan Province, China, which were derived from three genera (i.e., Glomus, Claroideoglomus, and Septoglomus). The five species of endomycorrhizal fungi included G. mosseae, G. multicaule, G. aggregatum, C. etunicatum, and S. constrictum, with the dominant species of endomycorrhizal fungi being G. mosseae and G. aggregatum. The results of this study were different from another investigation of endomycorrhizal fungi in an E. globulus plantation in Kunming City of Yunnan Province, which had been done by the same research team, and published in a separate paper. Six species of endomycorrhizal fungi were isolated from the bulk soil in an E. globulus plantation in Kunming City of Yunnan Province, which were derived from three genera (i.e., Glomus, Claroideoglomus and Septoglomus). The six species were G. mosseae, G. multicaule, G. aggregatum, C. etunicatum, S. constrictum, and Glomus hoi, with the dominant species being G. aggregatum. Many scholars have intensively studied the endomycorrhizal fungi of Eucalyptus, and it was found that the endomycorrhizal fungi resources of Eucalyptus were very abundant. Further, that the endomycorrhizal fungi species of Eucalyptus were variable for different regions and tree species (Tan et al., 2000; Zhu et al., 2001a; Zhu et al., 2001b; Zhong et al., 2001). In the Yunnan region, endomycorrhizal fungi species in the bulk soil of E. maidenii plantation and that of E. globulus plantation were different, thus, it is a key content toward matching tree species with endomycorrhizal fungi in a certain region.
In previous investigations of endomycorrhizal fungi for Eucalyptus, G. multicaule and G. hoi were not isolated, while G. multicaule and G. hoi were isolated from the bulk soil of Betula alnoides in the Yunnan region (Jing, 2015), and from the soil in the dry-hot valleys of Yunnan (Wu et al., 2014). It was revealed that the distribution of the two species of endomycorrhizal fungi was closely associated with the geographical environment, particularly the soil environment of Yunnan.

\section{Effects of the endomycorrhizal fungi on the growth and nutrient characteristics of Eucalyptus maidenii seedlings}

In this study, it was shown that the growth of roots (i.e., the number of secondary lateral roots and root activities) and aerial components of seedlings (i.e., seedling heights) of E. maidenii were significantly promoted by the third experimental treatment, where certain quantities of endomycorrhizal fungi spores were added to nursery substrates. These results were consistent with the promotional effects on the growth of E. grandis $\times$ E. urophylla, E. urophylla, and Macadamia ternifolia seedlings, all of which were inoculated by endomycorrhizal fungi (Zhong et al., 2001; Liu et al., 2005).

For 11 month old E. maidenii seedlings with an increased number of endomycorrhizal fungi spores in nursery substrates, the endomycorrhizal infection rate and intensity of the E. maidenii seedlings increased. The nitrogen, phosphorus, and potassium concentrations in the bulk soil also increased, as did the nitrogen concentration in the aerial components of seedlings, and phosphorus in the seedling roots. Furthermore, the concentrations of nutrients (i.e., nitrogen, phosphorus, and potassium) in the bulk soil and in the seedlings (i.e., roots, stems, and leaves) were significantly improved by the third experimental treatment.

The growth indices of the aerial components of the seedlings were significantly positively correlated with the nitrogen concentration of the seedlings. The indices of the nutrient absorption capacity of the seedlings (i.e., number of lateral roots and root activities) had a significantly positive correlation with the phosphorus concentration of the seedlings. Therefore, the promotional effect of endomycorrhiza for the growth of the E. maidenii seedlings was explained from the perspective of nutrient physiology. To summarize, the study of endomycorrhizal fungi for E. maidenii was done from the appearance to the mechanism, and the guidance of species and quantity of endomycorrhizal fungi spores for the cultivation of E. maidenii seedlings was provided. 
Future studies should develop single spore cultures for each of the five species isolated in the present study using the Trifolium repens method (Zhu et al., 2001a). Once single spore cultures are available, additional studies would allow further exploration of the mechanisms by which these endomycorrhizal fungi promote growth in E. maidenii seedlings. Further in depth research may provide a theoretical basis and practical guidance for optimal seedling cultivation in sustainable E. maidenii plantations.

\section{Conclusions}

In an E. maidenii plantation in Kunming, five species of endomycorrhizal fungi were identified and isolated from the bulk soil, where the dominant species of endomycorrhizal fungi were G. mosseae and $G$. aggregatum. We observed that when a certain quantity of endomycorrhizal fungi spores were added to the soil substrate, additional nutrients (i.e., nitrogen, phosphorus, and potassium) of the bulk soil were provided. Further, the nutrient (i.e., nitrogen, phosphorus, and potassium) absorption capacity of the seedling roots were enhanced, and the concentrations of nitrogen, phosphorus, and potassium in the seedlings were increased; thus, the seedling growth was promoted. The main endomycorrhizal fungi species that affected the nutrient concentration and growth of the E. maidenii seedlings were G. multicaule, G. aggregatum, and C. etunicatum.

\section{Availability of data and material}

All data generated or analyzed during this study are included in this published article.

\section{Competing in interests}

The authors declare that they have no competing interests.

\section{Author's contributions}

WXL, KXN, ZYW, CY, and CZL conceived and designed the study. WXL and KXN implemented the seedling cultivation, as well as the determination of nutrient concentration and growth traits of the seedlings. ZYW, CY, and CZL performed bulk soil sample collection, data analysis, and prepared the tables and figures. WXL drafted the manuscript. All authors reviewed and edited the manuscript.

\section{Acknowledgements}

We acknowledge Li Genqian for his assistance with experimental design, Wu Jianrong for instruction on the identification of the endomycorrhizal fungal spores, and the Professors of Southwest Forestry University in China.

\section{Funding}

This work was supported by grants from National Key Research and Development Project of China (2016YFD0600501).

\section{References}

An ZQ, Hendrix JW, Hershman DE \& Henson GT (1990) Evaluation of the "most probable number" (MPN)and wet-sieving methods for determining soil-borne populations of endogonaceous mycorrhizal fungi. Mycologia 82: 576-581. doi: $10.2307 / 3760048$.

Berch SM \& Kendrick B (1982) Vesicular-arbuscular mycorrhizae of southern Ontario ferns and fern-allies. Mycologia 74: 769-776. doi:10.1080/ 00275514.1982 .12021584$.

Chen YL, Gong MQ, Wang FZ \& Chen Y (1998) Effects of ECM and VAM fungi combined inoculation on the growth of Eucalyptus urophylla. Forest Research 11: 481-487.

Gong MQ, Chen Y, Wang FZ \& Ye Q (1997) Resources and distribution of VAM fungus communities in Eucalyptus forest in southern China. Forest Research 3: 54-59.

Hua XM (1995) Studies on mycorrhiza of forest trees. 1st ed. China Science and Technology Press, Beijing, China.

Huang Y, Huang BL, Lv CQ, Deng ZF \& Qin QF (2008) A study of growth effect of Eucalyptus seedlings inoculated with puffball epiphyte. Journal of Sichuan Forestry Science and Technology 5: 3438. doi:10.16779/j.cnki.1003-5508.2008.05.009.

Jing YB (2015) Arbuscular mycorrhizas of Betula alnoides plantations in tropical and sub-tropical regions of Yunnan. Yunnan University, Kunming, China.

Lapeyrie FF \& Chilvers GA (1985) An endomycorrhizal-ectomycorrhiza succession associated with enhanced growth by Eucalyptus dumosa seedlings planted in a calcareous soil. New Phytologist 100: 93-104.

Li HS (2000) Principles and techniques of plant physiological and biochemical experiments. 1st ed. Higher Education Press, Beijing, China.

Li XL \& Feng G (2001) Arbuscular mycorrhizal ecological physiology. 1st ed. Chinese Press, Beijing, China.

Liu FJ, Zhang Y, Xie LY \& Zeng M (2005) Effects of arbuscular mycorrhizal fungi on the growth 
and development of Macadamia plantlets. Chinese Journal of Tropical Crops 26: 16-19.

Lodge DJ \& Wentworth TR (1990) Negative associations among VA mycorrhizal fungi and some ectomycorrhizal fungi inhabiting the same root system. Oikos 57: 347-356. doi:10.2307/3565964.

Nicolson TH \& Schenck NC (1979) Endogonaceous mycorrhizal endophytes in Florida. Mycologia 71: $178-198$.

Omar C, Jose LS, Lee A, María CA \& Mario L (2018) Productivity gains from weed control and fertilization of short-rotation Eucalyptus plantations in the Venezuelan Western Llanos. Forest Ecology \& Management 430: 566-575. doi:10.1016/j.foreco.2018.07.050.

Redecker D, Schüßler A, Stockinger H, Stürmer SL, Morton JB \& Walker C (2013) An evidence-based consensus for the classification of arbuscular mycorrhizal fungi (Glomeromycota). Mycorrhiza 23: 515-531. doi:10.1007/s00572-013-0486-y.

Ren ZX, Bao XM, Yu JY \& Zhuo RD (2013) Current status, problems and countermeasures of Eucalyptus plantation fertilization practices in China. Eucalypt Science \& Technology 30: 52-59. doi:10.13987/j.cnki.askj.2013.04.011.

Schenck NC \& Perez Y (1988) Manual for the identification of VA mycorrhizal fungi. 2nd ed. Gainesville, Florida, USA.

Tan FH \& Wang YZ (2000) Investigation on exogenetic mycorrhizal species of Pinus and Eucalyptus in Sichuan. Journal of Sichuan Forestry Science and Technology 21: 65-69. doi:10.16779/j.cnki.10035508.2000.03.023.

Trappe JM \& Schenck NC (1982) Taxonomy of the fungi forming endomycorrhizae: Methods and principles of mycorrhizal research (ed. by Schenck
NC). American Phylopath Socst, St Paul, MN, USA.

Wang HR (2010) Introduction to Eucalyptus biology. 1 st ed. Science Press, Beijing, China.

Wang YH, Dong HQ, Chen JY, Ren JM, Nie CR \& Lin YF (2003) Effects of two fungi on growth of Eucalyptus urophylla. Soils and Fertilizers 1: 34-37. doi:10.3969/j.issn.1673-6257.2003.01.011.

Wu JR, Wang Y, Zhao CY, Lu QH, Gao Z, Wang F \& Ma HC (2014) AMF isolated from bombacaceae plants in dry and hot valley of Yunnan. Journal of Northwest A-F University (Natural Science Edition) 42: 205-210. doi:10.13207/j.cnki.jnwafu.2014.01.022.

Xiang XW, Wu LY \& Huang LT (2017) Discussion on the effects of different special topdressing fertilizer on Eucalyptus growth. South China Agriculture 11: 48-49. doi:10.19415/j.cnki.1673-890x.2017.08.28.

Zhong CL, Gong MQ, Xu DP, Chen Y, Wang FZ \& Nicholas M (2001) Effect of genotype and ectomycorrhizal fungal inoculation on growth of Eucalyptus trees. Forest Research 14: 181-187.

Zhou XJ (2011) Cutting propagation of Eucalyptus maidenii. Bulletin of Agricultural Science and Technology 7: 227-230.

Zhu TH, Zhang J, Hu TX, Li XW \& Liu YG (2001a) Mycorrhizae type associated with Eucalyptus in Sichuan and effect of forest density on mycorrhizal fungi. Journal of Sichuan Agricultural University 19: 222-224.

Zhu TH, Zhang J, Hu TX, Li XW \& Liu YG (2001b) The study on ectomycorrhizal fungi associated with Eucalyptus in Sichuan. Journal of Sichuan Agricultural University 19: 137-140. 